Retraction

\title{
Retracted: Evaluation of the Stability of the Total Antioxidant Capacity, Polyphenol Contents, and Starch Hydrolase Inhibitory Activities of Kombucha Teas Using an In Vitro Model of Digestion
}

\author{
Journal of Chemistry \\ Received 25 August 2016; Accepted 25 August 2016 \\ Copyright (c) 2016 Journal of Chemistry. This is an open access article distributed under the Creative Commons Attribution License, \\ which permits unrestricted use, distribution, and reproduction in any medium, provided the original work is properly cited.
}

Journal of Chemistry has retracted the article titled "Evaluation of the Stability of the Total Antioxidant Capacity, Polyphenol Contents, and Starch Hydrolase Inhibitory Activities of Kombucha Teas Using an In Vitro Model of Digestion" [1], as the High Performance Liquid Chromatography (HPLC) and microbiological results were questioned and it was found that the underlying data for this study are not available, and thus the results of the article are questionable.

\section{References}

[1] M. I. Watawana, N. Jayawardena, S. J. Ranasinghe, and V. Y. Waisundara, "Evaluation of the stability of the total antioxidant capacity, polyphenol contents, and starch hydrolase inhibitory activities of Kombucha teas using an in vitro model of digestion," Journal of Chemistry, vol. 2015, Article ID 684561, 9 pages, 2015. 


\title{
Evaluation of the Stability of the Total Antioxidant Capacity, Polyphenol Contents, and Starch Hydrolase Inhibitory Activities of Kombucha Teas Using an In Vitro Model of Digestion
}

\author{
Mindani I. Watawana, Nilakshi Jayawardena, Shakkya J. Ranasinghe, \\ and Viduranga $Y$. Waisundara
}

Functional Food Product Development Project, National Institute of Fundamental Studies, Hantane Road, 20000 Kandy, Sri Lanka

Correspondence should be addressed to Viduranga Y. Waisundara; viduranga@gmail.com

Received 7 September 2015; Revised 9 October 2015; Accepted 12 October 2015

Academic Editor: Dimitris P. Makris

Copyright (C) 2015 Mindani I. Watawana et al. This is an open access article distributed under the Creative Commons Attribution License, which permits unrestricted use, distribution, and reproduction in any medium, provided the original work is properly cited.

The objective of this study was to evaluate and compare antioxidant and starch hydrolase inhibitory activity of three different types of Kombucha beverages prepared by three pellicles with different microbial compositions. The fermentation process was carried out for 7 days and the assessments of antioxidant and starch hydrolase inhibitory activities as well as tea phenolic compounds were carried out. These parameters were also evaluated after subjecting the final fermented samples to gastric and duodenal digestion in an in vitro digestion model. The $\mathrm{pH}$ had a statistically significant decrease during the period of fermentation. The total phenolics content and antioxidant activities had increased during the fermentation process as well as when subjected to digestion. The starch hydrolase inhibitory activities also increased in a similar manner during the different phases. The $\alpha$-amylase and $\alpha$-glucosidase inhibitory activities showed statistically significant increases $(P<0.05)$ as the fermentation progressed, while an increase was observed after being subjected to pancreatic and duodenal digestion as well. All three types of tea showed a higher $\alpha$-amylase inhibitory activity than $\alpha$-glucosidase inhibitory activity.

\section{Introduction}

The interest towards conducting systematic studies on traditionally consumed food items for the purpose of maintaining good health and well-being has increased during recent times. Many of the traditional food products are known to possess bioactive components which enable them to be considered as functional foods. Essentially, this category of food products includes whole foods and fortified, enriched, or enhanced foods, which have a potentially beneficial effect on health when consumed as part of a varied diet on a regular basis, at effective levels [1]. Kombucha, a fermented tea beverage, has gained immense popularity throughout the world in recent times as a functional food, especially in Western and Mediterranean regions, primarily due to numerous associated health benefits such as anticancer, antidiabetic, anti-inflammatory, hepatoprotective, and detoxification as well as due to the ability to act as a probiotic and symbiotic beverage [2-4]. This beverage is traditionally prepared by fermenting sugared black tea with a symbiotic mixed culture of yeast and bacteria [5]. It is believed that this beverage originated in China and it is popular for its high antioxidant activity and starch hydrolase inhibitory activities which have been systematically demonstrated by many recent studies [5-8]. The period of fermentation is typically known to be a minimum of 3 days with a maximum of 60 days depending on the native practices, whereby the broth is filtered and consumed after the process [5]. The flavor of this tea varies widely from sparkling flavor to a mild vinegar-like taste [9]. The studies focusing on the antioxidant activity of the beverage have also demonstrated the possession of bioactive ingredients of therapeutic interest, mainly the polyphenols and secondary metabolites developed during the fermentation process itself.

The bacterial component of the Kombucha culture consists of strains such as Acetobacter xylinum, A. xylinoides, 
A. aceti, A. pausterianus, and Bacterium gluconicum [9]. The dominant yeast strains are Zygosaccharomyces bailii, Schizosaccharomyces pombe, Saccharomyces ludwigii, S. cerevisiae, Kloeckera spp., Torulaspora spp., and Pichia species [9, 10]. Many scientific studies have proven that yeast outnumber the bacterial count during the fermentation and it has also been discovered that the number of yeast and bacterial cells in the broth is more than the number of cells in the cellulosic pellicle $[8,10,11]$. The organic acids produced during the fermentation decrease the $\mathrm{pH}$ in the broth, which leads to acidity-induced oxygen starvation. Due to this process, the number of viable pathogenic microbial cells, if present at all, decreases as well, resulting in a beverage which is safe for consumption despite being of microbial origin [11]. The acetic acid bacteria present in this consortium have the ability to produce cellulose which forms a zoogleal mat, where this network enhances the association between bacteria and yeast [12]. Caffeine and related xanthines found in tea have the ability to stimulate the synthesis of this cellulose by the bacteria [7, 12]. Many factors such as climate, geographic location, local species of bacteria and yeast, and source of inoculum have been known to play a significant role in deciding the microbial composition of the Kombucha culture [12].

One objective of this study was to evaluate the enhancement of the antioxidant activity, the changes in polyphenolic contents, and the starch hydrolase inhibitory activity in sugared black tea fermented with three Kombucha cultures of differed microbial composition. The obtained results were compared with the unfermented values of tea prior to the fermentation process. Additionally it was necessary to quantify and study the bioaccessible antioxidant capacity and starch hydrolase inhibitory activity. This is essentially the antioxidant and starch hydrolase inhibitory properties which are released from the fermented beverage and subsequently released for absorption during the intestinal and duodenal digestion processes [13]. An in vitro digestion model was utilized for this purpose, where the fermented tea samples were subjected to gastric and duodenal digestion phases. Measurement of the total antioxidant capacity (TAC), total polyphenolics content, and starch hydrolase inhibitory activity before and after the in vitro digestion phases were quantified of all three different Kombucha teas prepared from the varied strains.

\section{Materials and Methods}

The bacterial and fungi strains pellicular mats used for the study were verified and authenticated according to the method by Marsh et al., [8] using DNA amplification and high-throughput sequencing. The results are reported in Table 1. Black tea dust was obtained from Watawala Plantations, Sri Lanka. All other reagents, chemicals, and HPLC standards used for the study were purchased from Sigma Chemicals (St. Louis, MO, USA).

2.1. Preparation of Kombucha Teas and Determination of the $\mathrm{pH}$ and Titratable Acidity (TA). One gram of black tea (Camellia sinensis) dust was added to $100 \mathrm{~mL}$ of boiling water and infused for $5 \mathrm{~min}$ after which they were filtered through a sterile sieve. Sucrose (10\%) was dissolved in each beverage and the preparation was left to cool to room temperature at $24 \pm 3^{\circ} \mathrm{C}$. The cooled tea was aseptically inoculated with each of the freshly grown tea fungi for 7 days. The fermentation was carried out at $24 \pm 3^{\circ} \mathrm{C}$. Sampling was carried out only once per day in order to avoid contamination. The fermented teas were centrifuged at $7240 \times \mathrm{g}$ for $10 \mathrm{~min}$ prior to the assays and analyses. The $\mathrm{pH}$ values were measured with a hand-held pH meter (Testo $206 \mathrm{PH}$, Keison, London, UK), while the TA was measured according to the method by Chen and Liu [10].

2.2. Enumeration of Bacteria and Fungi Population in the Broth and Pellicle. Enumerations of the overall population of bacteria and yeast in the broth and pellicle of the fermented beverages were determined according to the method by Chen and Liu [10]. Both figures were expressed as colony-forming units per $\mathrm{mL}(\mathrm{cfu} / \mathrm{mL})$.

2.3. Determination of the Total Phenolics Content and Antioxidant Activity. The method by Huang et al. [14] was used for determining the total phenolics content and the Oxygen Radical Absorbance Capacity (ORAC) assay was carried out according to Prior et al. [15]. Results for the total phenolics content were expressed as milligrams of gallic acid equivalents (GAE) per milliliters (mg GAE/mL), while the ORAC values were expressed as micromoles of trolox equivalents (TE) per milliliters $(\mu \mathrm{mol} \mathrm{TE} / \mathrm{mL})$. The di(phenyl)(2,4,6-trinitrophenyl)iminoazanium (DPPH) and superoxide radical scavenging activity assays were carried out according to the method described by Lee et al. [5]. All assays were carried out using the Synergy HTX multimode microplate reader and Gen5 software (Biotek, Winooski, VT, USA).

2.4. Determination of the $\alpha$-Amylase and $\alpha$-Glucosidase Inhibitory Activities. The $\alpha$-amylase inhibitory activity was evaluated according to the method by Liu et al. [16] while the $\alpha$-glucosidase inhibitory activity was carried out according to the method by Lee et al. [17]. Acarbose was used as the positive control for both assays and the data were expressed as $\mathrm{IC}_{50}(\mathrm{mg} / \mathrm{mL})$.

2.5. In Vitro Digestion Process. The in vitro digestion model was adapted from Ryan et al. [18]. In brief, the fermented tea samples at day 7 of the process were transferred to clean amber bottles and mixed with saline (balanced salt solution) to create a final volume of $20 \mathrm{~mL}$. The samples were acidified to $\mathrm{pH} 2.0$ with $1 \mathrm{~mL}$ of a porcine pepsin preparation $(0.04 \mathrm{~g}$ pepsin in $1 \mathrm{~mL} 0.1 \mathrm{M} \mathrm{HCl}$ ) and incubated at $37^{\circ} \mathrm{C}$ in a shaking water bath at $3000 \times \mathrm{g}$ for $1 \mathrm{~h}$. After gastric digestion, $500 \mu \mathrm{L}$ of each sample was extracted and stored at $-20^{\circ} \mathrm{C}$. The $\mathrm{pH}$ was then increased to 5.3 with $0.9 \mathrm{M}$ sodium bicarbonate followed by the addition of $200 \mu \mathrm{L}$ of bile salts glycodeoxycholate $(0.04 \mathrm{~g}$ in $1 \mathrm{~mL}$ saline), taurodeoxycholate $(0.025 \mathrm{~g}$ in $1 \mathrm{~mL}$ saline), taurocholate $(0.04 \mathrm{~g}$ in $1 \mathrm{~mL}$ saline), and $100 \mu \mathrm{L}$ of pancreatin $(0.04 \mathrm{~g}$ in $500 \mu \mathrm{L}$ saline). The $\mathrm{pH}$ of each sample was increased to 7.4 with $1 \mathrm{M} \mathrm{NaOH}$. Samples were incubated 


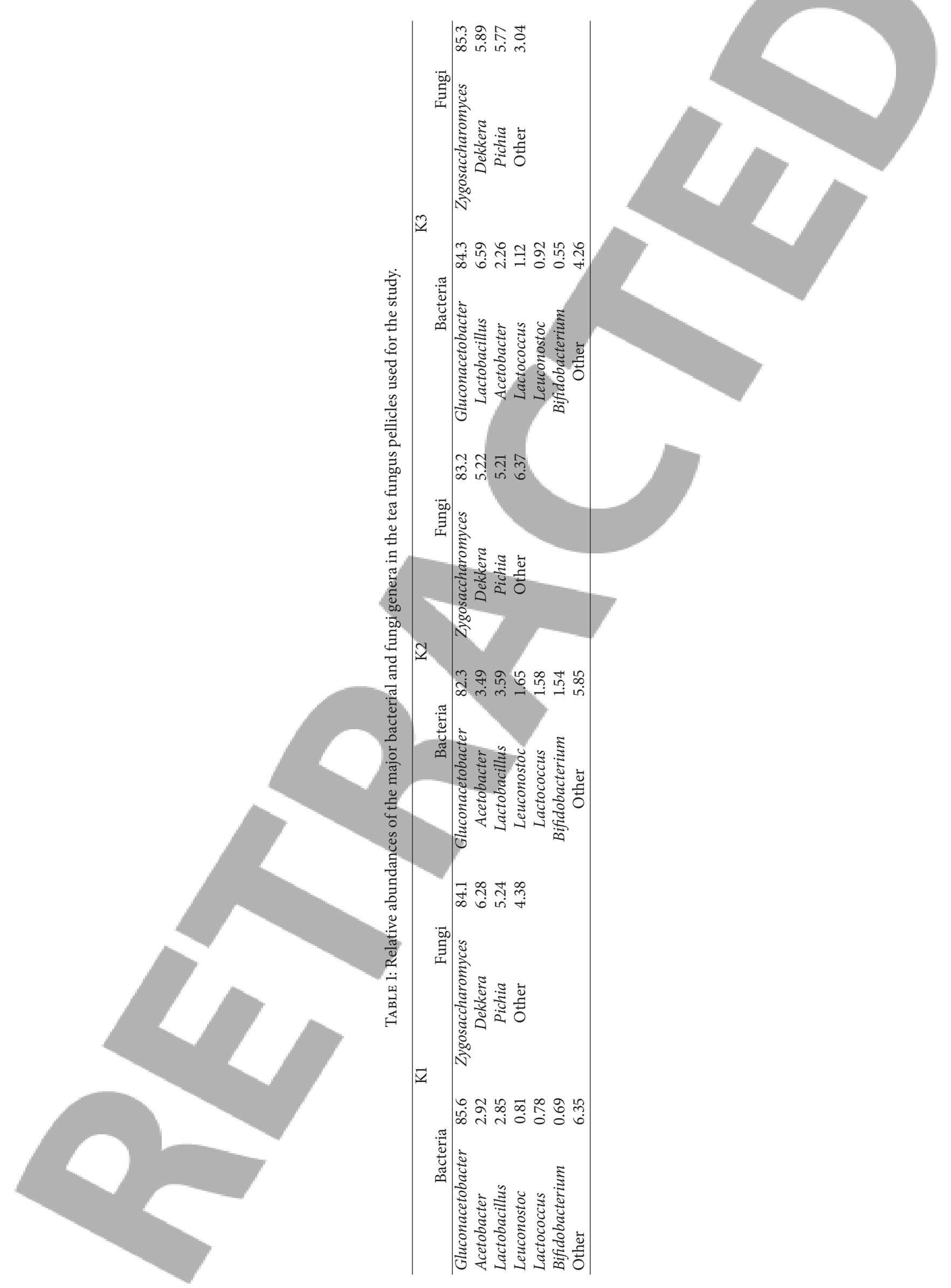


in a shaking water bath at $95 \mathrm{rpm}$ at $37^{\circ} \mathrm{C}$ for $2 \mathrm{~h}$ to complete the intestinal phase of the in vitro digestion process. After the intestinal phase, $500 \mu \mathrm{L}$ of each sample was extracted and stored at $-20^{\circ} \mathrm{C}$.

2.6. High Performance Liquid Chromatography (HPLC) Determination of the Phenolic Compounds. A Shimadzu LC2010 HPLC system (Kyoto, Japan) equipped with an SPD-M10AVP diode array detector (Kyoto, Japan) and a phenomenex Luna C-18(2) column $(4.6 \mathrm{~mm}$ i.d. $\times 25 \mathrm{~cm}, 5 \mu \mathrm{m})$ was used for the quantification of (-)-epicatechin (EC), (-)epicatechin-3-gallate (ECG), (-)-epigallocatechin (EGC), and (-)-epigallocatechin-3-gallate (EGCG), theaflavin (TF), and gallic acid (GA). A gradient profile using two solvents was applied following the method by Jayabalan et al. [19] with a few modifications for the quantification of EC, ECG, EGC, EGCG, and GA. The solvents used were as follows: solvent A: $8 \%$ aqueous formic acid; solvent $\mathrm{B}$ : acetonitrile/methanol $(10: 90, \mathrm{v} / \mathrm{v})$. A flow rate of $0.9 \mathrm{~mL} / \mathrm{min}$ was maintained. The gradient was as follows: $0 \mathrm{~min}-20 \% \mathrm{~B} ; 7 \mathrm{~min}-35 \% \mathrm{~B}$; $14 \mathrm{~min}-45 \% \mathrm{~B} ; 21 \mathrm{~min}-65 \% \mathrm{~B} ; 25 \mathrm{~min}-85 \% \mathrm{~B} ; 32 \mathrm{~min}-$ $95 \% \mathrm{~B}$. The TF content was determined according to the method by Thanaraj and Seshadri [20] using the same HPLC setup which was used to quantify the epicatechin isomers. The wavelengths of the diode array detector were set at 260, 280 , and $320 \mathrm{~nm}$ for monitoring of the phenolic compounds. The concentrations of all the compounds in the extracts were quantified using standard curves and expressed as micrograms per $\mathrm{mL}(\mu \mathrm{g} / \mathrm{mL})$.

2.7. Statistical Analysis. IBM SPSS Statistics version 21.0 released in 2012 (IBM Corp., Armonk, NY, USA) for Windows was used for the statistical analyses. Results were calculated and expressed as mean \pm standard error mean (SEM) of $\geq 3$ independent analyses. $P$ values of $<0.05$ were considered to be significant.

\section{Results and Discussion}

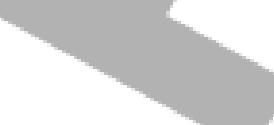

The initial values of all the analytical parameters prior to the fermentation process are indicated as day 0 in Tables $1-3$ and Figures 1-3. Sample results at day 7 are considered as the values prior to the digestion process, which are subsequently subjected to the pancreatic and duodenal digestion phases.

\subsection{Changes in Population of Viable Bacteria and Fungi.} Table 2 shows the changes of the composition of the overall population of bacteria and yeast present in the pellicle prior to fermentation, on day 1 and day 7 , as well as in the broth on days 1 and 7 . In all three Kombucha tea types, an increase in the overall bacteria and yeast population was observed. The increase in the bacteria and yeast population can be correlated to the fact that these microbes have the ability to utilize the substrate and successfully and thrive in the given environment. In addition, bacterial and fungi proportions of the fermented teas matched those of the corresponding pellicle, thereby suggesting that the fungal composition of the cellulosic pellicle used to inoculate the tea is the key determinant. Gluconacetobacter was generally observed to be the common and most populated bacterial entity in all three types of Kombucha pellicles. In previous studies, it has been identified as the key bacterial strain which enhances the bioaccessibility of polyphenols and antioxidant activities in Kombucha beverage [11]. According to Table 2, the cell concentrations of bacteria and yeast in the broth were higher than the cell concentrations in the cellulose pellicle. The Lactobacillus spp. present in all three pellicles may possess potential therapeutic properties including acting as a probiotic organism. Such microorganisms are known to provide a balance in intestinal microbiota, normalizing processes in gut and boosting the immune system [21]. The presence of both Gluconacetobacter and Lactobacillus spp. may also contribute to the fact that the antioxidant activity of the beverages was primarily imparted due to the metabolic activities of these two microbial genera as shown by previous studies $[12,21,22]$.

3.2. $p H$ and TA. Figure 1 shows the $\mathrm{pH}$ values of the samples on days 0,1 , and 7 as well as the results when the fermented samples are subjected to pancreatic and duodenal digestion. A statistically significant decrease $(P<0.05)$ was observed in the $\mathrm{pH}$ of all three types of Kombucha teas during the period of fermentation starting from day 1 onwards, as compared with their unfermented counterparts on day 0. Compared with the sample values at day 7 , a statistically significant $(P<0.05)$ change in the $\mathrm{pH}$ was observed when the teas were subjected to the gastric and duodenal digestion phases. K1 displays a statistically significantly lower $\mathrm{pH}(P<0.05)$ than its nondigested counterpart, whereas K2 and K3 display statistically significantly higher $(P<0.05)$ values. Prior to the fermentation, the $\mathrm{pH}$ of all three teas remained between 6.4 and 6.5. By day 7 of the fermentation period, the $\mathrm{pH}$ of the teas varied between 4.8 and 4.5 . K1 was observed to be the least acidic of the three teas at the end of the fermentation process with a $\mathrm{pH}$ value of 4.8 while $\mathrm{K} 2$ and $\mathrm{K} 3$ had a value of 4.5. The decrease in $\mathrm{pH}$ during the fermentation process would be due to the production of organic acids by the yeast and bacteria present in the tea fungus. The decrease in $\mathrm{pH}$ can be beneficial in terms of maintaining the bioactivity and preventing the chemical degradation of phenolic compounds. Previous studies have proven that the organic acids produced during the fermentation are gluconic acid, glucuronic acid, L-lactic acid, malic acid, tartaric acid, malonic acid, citric acid, and oxalic acid $[22,23]$. The TA of the unfermented teas ranged between 0.14 and 0.15 , and at the end of the fermentation process, the TA values ranged between 2.5 and 2.7 which are statistically significant increase $(P<0.05)$ compared with the unfermented samples. After pancreatic digestion the TA had statistically significant increase $(P<$ 0.05 ) in all 3 samples as compared with the day 7 fermented sample. Following duodenal digestion, the TA values have shown a statistically significant decrease $(P<0.05)$ compared with the fermented sample at day 7. According to Reiss [24], the optimum consumable acidity level of a beverage is $4.0-$ $4.5 \mathrm{~g} / \mathrm{L}$; thus all three tea types are within the range of the acceptable TA level and can be acceptable for consumption. 
TABLE 2: Changes to the composition of the overall population of bacteria and fungi present in the broth and the pellicle prior to fermentation (day 0 ) and on day 1 and day 7.

\begin{tabular}{|c|c|c|c|c|c|}
\hline & \multirow{2}{*}{ Sample } & \multirow{2}{*}{ Microorganisms } & \multicolumn{3}{|c|}{ Days (population of microorganisms) } \\
\hline & & & $0(\mathrm{cfu} / \mathrm{mL})$ & $1(\mathrm{cfu} / \mathrm{mL})$ & $7(\mathrm{cfu} / \mathrm{mL})$ \\
\hline \multirow{6}{*}{ Broth } & \multirow{2}{*}{ K1 } & Bacteria & - & $7.1 \pm 0.2 \times 10^{7}$ & $8.4 \pm 0.2 \times 10^{8}$ \\
\hline & & Fungi & - & $6.6 \pm 0.1 \times 10^{8}$ & $7.2 \pm 0.2 \times 10^{9}$ \\
\hline & \multirow{2}{*}{ K2 } & Bacteria & - & $9.6 \pm 0.1 \times 10^{6}$ & $4.9 \pm 0.1 \times 10^{9}$ \\
\hline & & Fungi & - & $7.2 \pm 0.1 \times 10^{6}$ & $5.6 \pm 0.2 \times 10^{9}$ \\
\hline & \multirow{2}{*}{ K3 } & Bacteria & - & $4.9 \pm 0.5 \times 10^{6}$ & $7.9 \pm 0.2 \times 10^{9}$ \\
\hline & & Fungi & - & $9.9 \pm 0.2 \times 10^{6}$ & $8.2 \pm 0.3 \times 10^{9}$ \\
\hline \multirow{6}{*}{ Pellicle } & \multirow{2}{*}{$\mathrm{K} 1$} & Bacteria & $4.7 \pm 0.1 \times 10^{5}$ & $2.9 \pm 0.1 \times 10^{6}$ & $8.5 \pm 0.1 \times 10^{8}$ \\
\hline & & Fungi & $4.8 \pm 0.2 \times 10^{5}$ & $6.5 \pm 0.1 \times 10^{5}$ & $7.6 \pm 0.1 \times 10^{7}$ \\
\hline & \multirow{2}{*}{ K2 } & Bacteria & $3.8 \pm 0.1 \times 10^{5}$ & $6.9 \pm 0.1 \times 10^{5}$ & $9.5 \pm 0.2 \times 10^{7}$ \\
\hline & & Fungi & $3.9 \pm 0.1 \times 10^{5}$ & $6.8 \pm 0.1 \times 10^{6}$ & $9.6 \pm 0.3 \times 10^{7}$ \\
\hline & \multirow{2}{*}{ K3 } & Bacteria & $1.9 \pm 0.2 \times 10^{5}$ & $7.5 \pm 0.5 \times 10^{5}$ & $9.6 \pm 0.1 \times 10^{7}$ \\
\hline & & Fungi & $2.2 \pm 0.1 \times 10^{5}$ & $7.2 \pm 0.2 \times 10^{6}$ & $8.2 \pm 0.1 \times 10^{7}$ \\
\hline
\end{tabular}

TABLE 3: Changes in the polyphenol contents in the three Kombucha cultures throughout the 7-day period of analysis expressed as mean \pm SEM. ${ }^{*} P<0.05$ versus the value of each tea at day $0 .{ }^{\dagger} P<0.05$ versus the value of each tea at day 7.

\begin{tabular}{|c|c|c|c|c|c|c|}
\hline \multirow{2}{*}{ Kombucha } & \multirow{2}{*}{ Polyphenol $^{\mathrm{a}}$} & \multicolumn{5}{|c|}{ Days/phase of digestion } \\
\hline & & $0(\mu \mathrm{g} / \mathrm{mL})$ & $1(\mu \mathrm{g} / \mathrm{mL})$ & $7(\mu \mathrm{g} / \mathrm{mL})$ & Pancreatic $(\mu \mathrm{g} / \mathrm{mL})$ & Duodenal $(\mu \mathrm{g} / \mathrm{mL})$ \\
\hline \multirow{6}{*}{1} & EGCG & $26.5 \pm 1.3$ & $27.5 \pm 1.1$ & $36.9 \pm 1.5^{*}$ & $37.5 \pm 1.6^{*}$ & $41.5 \pm 2.1^{* \dagger}$ \\
\hline & EGC & $27.8 \pm 1.2$ & $27.9 \pm 1.1$ & $31.2 \pm 1.1^{*}$ & $32.5 \pm 1.3^{*}$ & $34.1 \pm 1.1^{* \dagger}$ \\
\hline & ECG & $10.8 \pm 1.1$ & $11.2 \pm 1.2$ & $13.6 \pm 1.5^{*}$ & $13.9 \pm 1.6^{*}$ & $14.8 \pm 1.2^{*}$ \\
\hline & EC & $9.8 \pm 1.4$ & $10.5 \pm 1.2$ & $12.9 \pm 1.3^{*}$ & $13.9 \pm 1.1^{*}$ & $14.8 \pm 1.0^{* \dagger}$ \\
\hline & $\mathrm{TF}$ & $12.6 \pm 1.2$ & $13.9 \pm 1.1$ & $15.8 \pm 1.0^{*}$ & $16.7 \pm 1.1^{*}$ & $17.9 \pm 2.5^{* \dagger}$ \\
\hline & GA & $31.5 \pm 1.9$ & $36.8 \pm 1.1^{*}$ & $39.7 \pm 1.5^{*}$ & $40.1 \pm 1.9^{*}$ & $46.7 \pm 1.7^{* \dagger}$ \\
\hline \multirow{6}{*}{2} & EGCG & $26.5 \pm 1.3$ & $28.4 \pm 1.2$ & $35.9 \pm 1.6^{*}$ & $36.8 \pm 1.4^{*}$ & $40.2 \pm 1.9^{* \dagger}$ \\
\hline & EGC & $27.8 \pm 1.2$ & $28.7 \pm 1.2$ & $33.2 \pm 1.2^{*}$ & $34.5 \pm 1.6^{*}$ & $36.2 \pm 1.4^{* \dagger}$ \\
\hline & ECG & $10.8 \pm 1.1$ & $12.5 \pm 1.1$ & $14.9 \pm 1.3^{*}$ & $14.9 \pm 1.2^{*}$ & $15.9 \pm 1.1^{* \dagger}$ \\
\hline & EC & $9.8 \pm 1.4$ & $14.8 \pm 1.4$ & $15.4 \pm 1.2^{*}$ & $15.9 \pm 1.2^{*}$ & $16.8 \pm 1.0^{* \dagger}$ \\
\hline & $\mathrm{TF}$ & $12.6 \pm 1.2$ & $14.8 \pm 1.0$ & $16.9 \pm 1.3^{*}$ & $17.1 \pm 1.3^{*}$ & $18.5 \pm 2.0^{* \dagger}$ \\
\hline & GA & $31.5 \pm 1.9$ & $37.2 \pm 1.2$ & $41.6 \pm 1.6^{*}$ & $42.9 \pm 1.7^{*}$ & $47.6 \pm 1.2^{* \dagger}$ \\
\hline \multirow{6}{*}{3} & EGCG & $26.5 \pm 1.3$ & $27.6 \pm 1.5$ & $36.1 \pm 1.5^{*}$ & $37.9 \pm 1.6^{*}$ & $41.1 \pm 1.1^{* \dagger}$ \\
\hline & EGC & $27.8 \pm 1.2$ & $28.1 \pm 1.5$ & $34.9 \pm 1.2^{*}$ & $35.9 \pm 1.3^{*}$ & $42.9 \pm 1.2^{* \dagger}$ \\
\hline & ECG & $10.8 \pm 1.1$ & $13.9 \pm 1.0$ & $15.2 \pm 1.1^{*}$ & $15.4 \pm 1.0^{*}$ & $17.4 \pm 1.1^{* \dagger}$ \\
\hline & $\mathrm{EC}$ & $9.8 \pm 1.4$ & $15.1 \pm 1.2$ & $15.9 \pm 1.3^{*}$ & $16.1 \pm 1.0^{*}$ & $16.7 \pm 1.1^{* \dagger}$ \\
\hline & $\mathrm{TF}$ & $12.6 \pm 1.2$ & $15.1 \pm 1.1$ & $17.9 \pm 1.2^{*}$ & $18.0 \pm 1.2^{*}$ & $18.9 \pm 1.1^{* \dagger}$ \\
\hline & $\mathrm{GA}$ & $31.5 \pm 1.9$ & $38.5 \pm 1.5$ & $42.1 \pm 1.6^{*}$ & $43.6 \pm 1.2^{*}$ & $48.3 \pm 1.2^{* \dagger}$ \\
\hline
\end{tabular}

${ }^{a}$ The denoted abbreviations are as follows: (-)-epicatechin (EC), (-)-epicatechin-3-gallate (ECG), (-)-epigallocatechin (EGC), and (-)-epigallocatechin-3gallate (EGCG), theaflavin (TF), and gallic acid (GA).

3.3. Total Phenolics Content. The total phenolics contents are shown in Figure 2(a). The values of the unfermented teas varied between 470 and $476 \mathrm{mg}$ GAE/mL. Following the initiation of the fermentation process, the total phenolic content shows a statistically significant increase $(P<0.05)$ in all 3 fermented samples compared with their unfermented counterparts. When the teas were subjected to the in vitro digestion, statistically significant increases $(P<0.05)$ were observed in all 3 samples after intestinal digestion. In addition, statistically significant increases $(P<0.05)$ were observed in the total phenolics contents following the duodenal digestion as compared with the undigested sample at day
7 of the fermentation as well. The reason for the increase in total phenolics content during the fermentation process has been explained by Blanc [25], where it was demonstrated that the bacteria and yeast present in the Kombucha microbial consortium have the ability to liberate enzymes, such as phytase which has the capability of breaking down the cellulosic backbone of Camellia sinensis to release polyphenol compounds. Partial oxidation of polyphenols can be observed when the tea is fermented for a longer period of 1-2 months, resulting in a decrease in the total phenolics content and the antioxidant potential [26]. Thus, extended periods of fermentation can lead to the accumulation of unwanted 


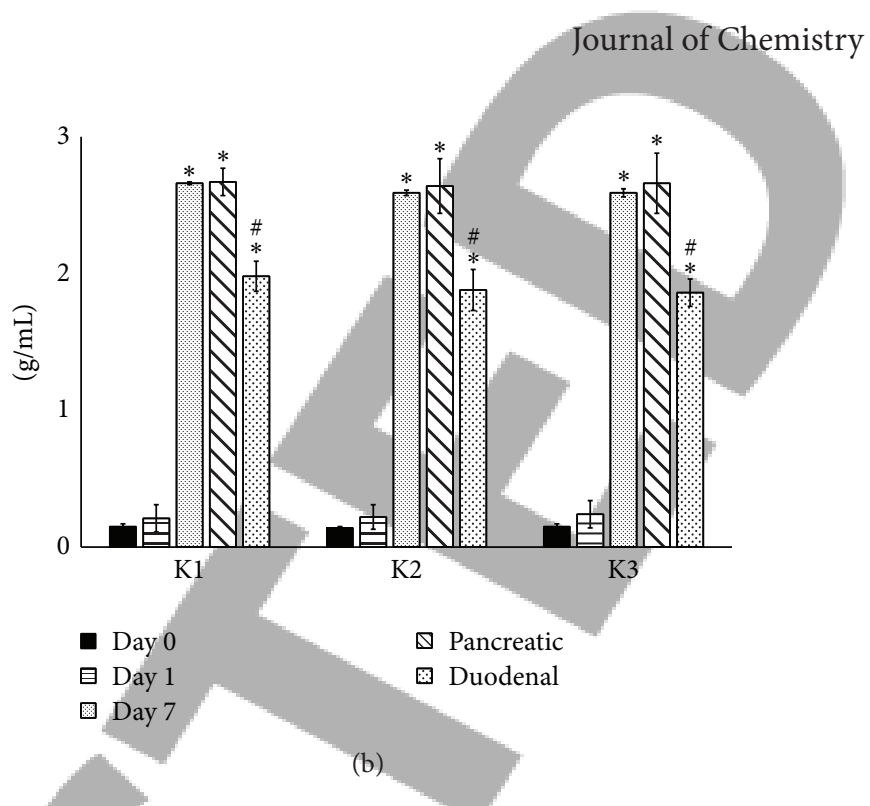

(a)

Figure 1: Changes in the (a) $\mathrm{pH}$ and (b) titratable acidity values of the three Kombucha beverages. Error bars represent the SEM. ${ }^{*} P<0.05$ versus the value at day $0 .{ }^{\#} P<0.05$ versus the value at day 7 (prior to being subjected to the digestion phases).

metabolites, and, therefore, the beverage may be deemed as therapeutically inadequate for imparting the required health benefits.

\subsection{ORAC, DPPH EC $C_{50}$, and Superoxide Scavenging Activities.}

The ORAC, DPPH EC $\mathrm{E}_{50}$, and superoxide scavenging activity results are shown in Figures $2(\mathrm{~b})-2(\mathrm{~d})$. In observing the ORAC results, statistically significant increases $(P<0.05)$ were observed in all 3 samples as the fermentation progresses, in comparison to the unfermented tea samples. At the unfermented stage all three tea samples had ORAC values in ranging from 1840 to $1880 \mu \mathrm{mol} \mathrm{TE} / \mathrm{mL}$. As the fermentation progressed, the ORAC values had increased. By day 7 of the fermentation process, the ORAC value for all teas was within a range of $2460-2640 \mu \mathrm{mol} \mathrm{TE} / \mathrm{mL}$. In comparing the values during the digestion processes, statistically significant increases $(P<0.05)$ were observed at both phases. It was noted that $\mathrm{K} 3$ had the highest ORAC value among all 3 fermented samples by the end of the fermentation process. An increase in the ORAC value represents the maintenance of the antioxidant potential throughout the fermentation period and this could be of therapeutic importance. It is also known that the oxidation of the polyphenols can result in the formation of stable intermediates which demonstrates strong antioxidant activity [27]. However, in this sample, the increase in the ORAC value was less than $\mathrm{K} 1$ and $\mathrm{K} 2$ in the duodenal digestion phases as compared with the undigested counterparts. Nevertheless, the final ORAC values of all three types of teas were within a comparable range at the end of the digestion phases. The $\mathrm{DPPH} \mathrm{EC}_{50}$ values of the 3 fermented Kombucha teas remained within the range of $56-59 \mathrm{mg} / \mathrm{kg}$ by day 7. As for the $\mathrm{DPPH} \mathrm{EC}_{50}$ values and the superoxide scavenging activities, the trend was not as clear as in the instances of the ORAC assay. A better correlation between the total phenolics content and the ORAC value was observed in comparison to the correlation between $\mathrm{DPPH} \mathrm{EC}_{50}$ and superoxide scavenging values. This better correlation could be due to the fact that the phenolic compounds present in all three types of tea samples may possess a better scavenging activity of peroxide radicals which are generated during the ORAC assay.

3.5. Starch Hydrolase Inhibitory Activity. The results obtained for starch hydrolase inhibitory activity are shown in Figure 3. In all three tea samples statistically significant increases $(P<0.05)$ in the $\alpha$-amylase inhibitory activity and $\alpha$ glucosidase activity were observed following the completion of the fermentation process. Prior to fermentation the $\alpha$ amylase inhibitory activity of all three Kombucha samples remained in the range of $55-56 \mu \mathrm{g} / \mathrm{mL}$ in terms of the $\mathrm{IC}_{50}$ value. As the fermentation progressed, the inhibitory activity has increased in a statistically significant $(P<0.05)$ manner. When subjected to pancreatic digestion, the $\alpha$-amylase inhibitory activity remains more so the same compared with the undigested counterpart. However, after duodenal digestion the $\alpha$-amylase inhibitory activity displayed statistically significant increases $(P<0.05)$ compared with the undigested sample at day 7 of the fermentation process. The $\alpha$-glucosidase inhibitory activity in the unfermented teas ranged between 69 and $70 \mu \mathrm{g} / \mathrm{mL}$ in terms of $\mathrm{IC}_{50}$ value. As the fermentation progressed, the inhibitory activity has shown statistically significant increases $(P<0.05)$. When the fully fermented samples were subjected to pancreatic digestion, the $\alpha$-glucosidase inhibitory activity was observed to be similar to the undigested counterpart. When it was subjected to duodenal digestion, statistically significant decrease $(P<0.05)$ in the $\mathrm{IC}_{50}$ value was observed, as compared with the unfermented sample. When considering the results obtained for the three Kombucha strains used in this study, it can be noted that the $\alpha$-glucosidase inhibitory activity of K3 after duodenal digestion was higher than the other two strains. In comparing $\alpha$-amylase inhibitory activity and $\alpha$ glucosidase inhibitory activities in all three tea samples it can be noted that the increase in $\alpha$-amylase inhibitory activity 

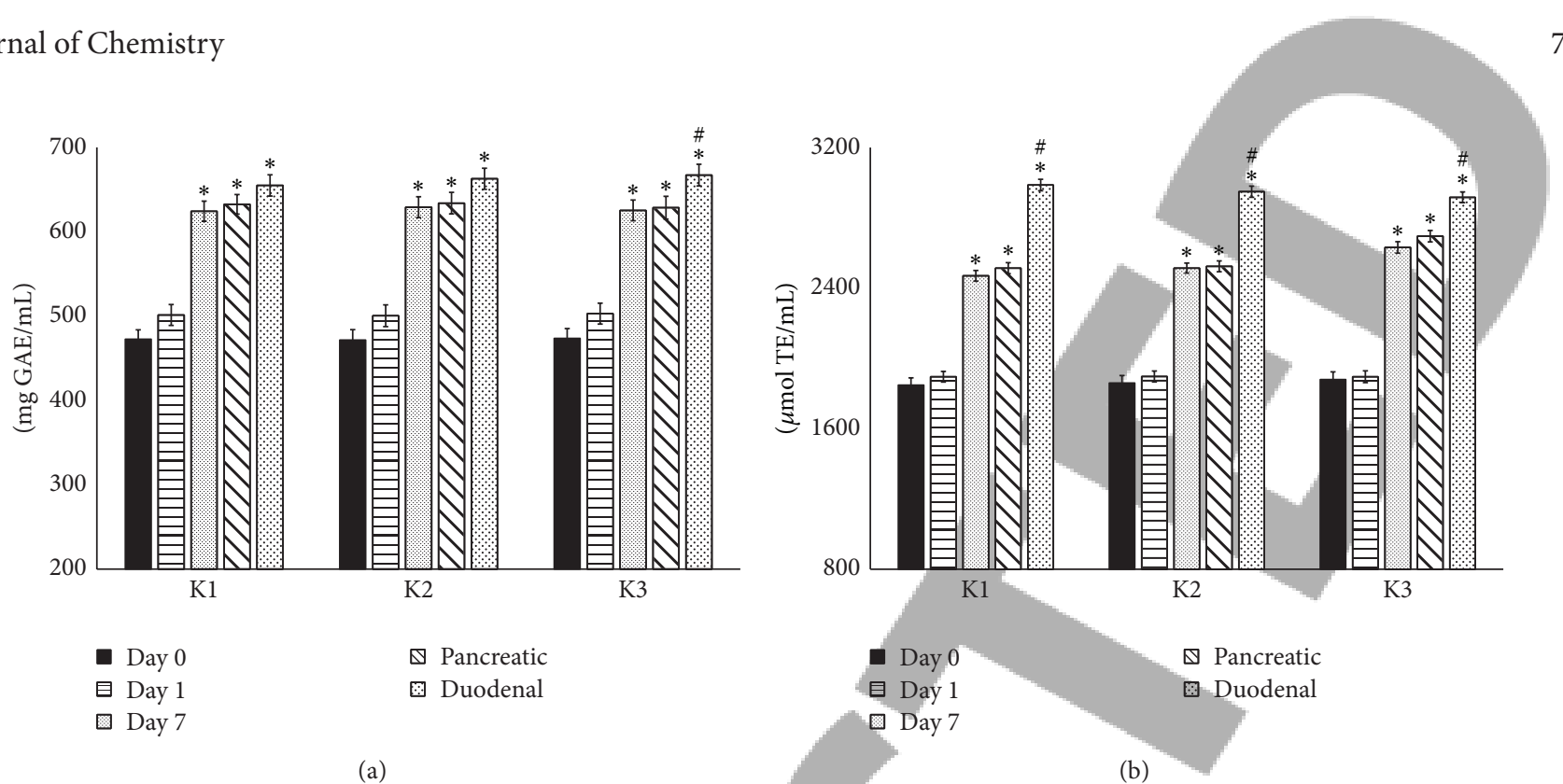

(a)

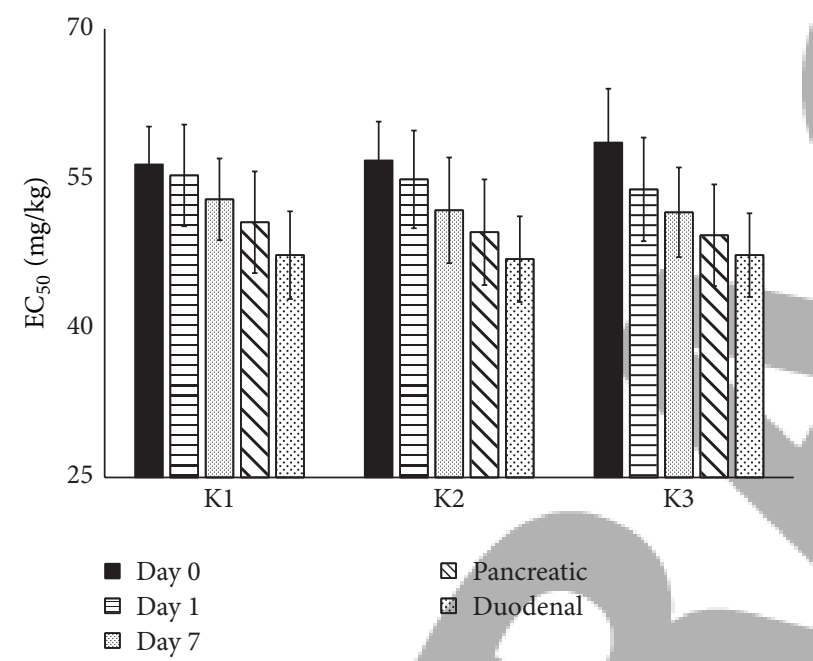

(c)

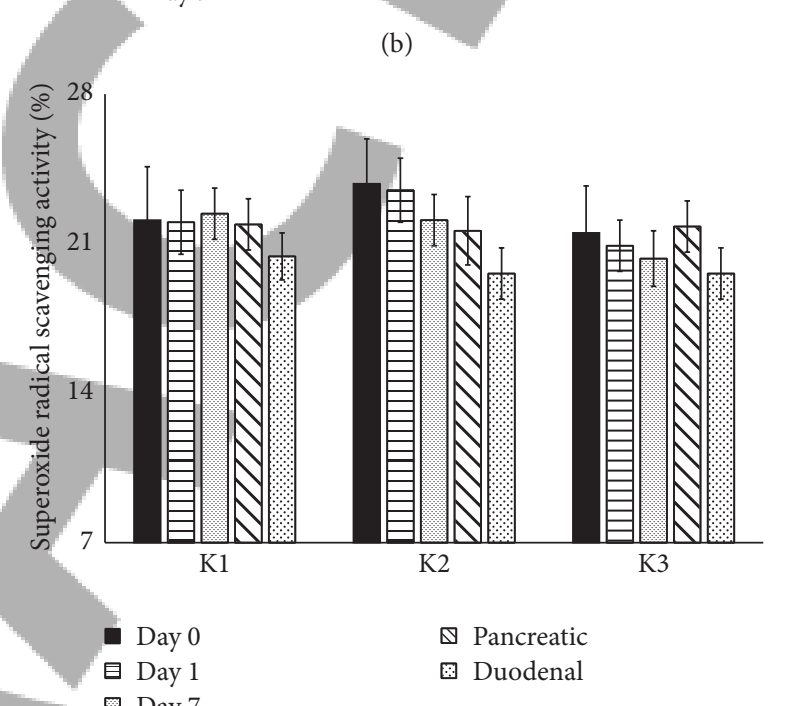

(d)

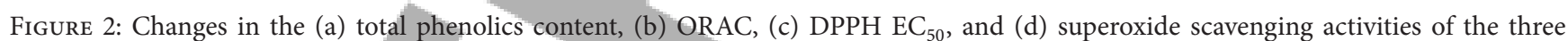
Kombucha beverages. Error bars represent the SEM. ${ }^{*} P<0.05$ versus the value at day $0 .{ }^{\#} P<0.05$ versus the value at day 7 (prior to being subjected to the digestion phases).

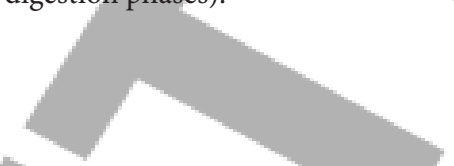

is higher than the $\alpha$-glucosidase inhibitory activity. Thus, it may be concluded that the tea fungus has the ability to enhance the $\alpha$-amylase inhibitory activity better than the $\alpha$-glucosidase inhibitory activity. $\alpha$-amylase is required for the subsequent reactions of $\alpha$-glucosidase. Therefore, the conclusion above may be considered as an important finding in terms of therapeutic effects of the Kombucha beverages. The observations also throw light on the therapeutically beneficial effects of these teas, since the enhancement of the inhibitors has the ability to retard glucose absorption by inhibition the enzymes $\alpha$-amylase and $\alpha$-glucosidase, which are found in the intestinal brush border $[16,17]$. Thus, it has an enhanced ability to prevent the breakdown of starch and the subsequent curbing of glucose release into the physiological system of the body.
3.6. Changes in the Tea Polyphenol Quantities. The changes in the tea polyphenol contents are shown in Table 3. It can be observed that all EGCG, EGC, ECG, EC, TF, and GA showed a statistically significant increase $(P<0.05)$ by day 7 compared with day 0 or the unfermented counterpart, in all three types of Kombucha teas. There was also a statistically significant increase $(P<0.05)$ in the polyphenol contents after subjecting the teas to pancreatic and duodenal digestions. Samples subjected to duodenal digestion showed the highest value of polyphenol content for all three tea types. Quantities of these phenolic compounds were reflective of the total phenolics contents displayed in Figure 2(a). It was heartening to observe an increase in the tea catechins themselves as a result of the fermentation process as well as the pancreatic and duodenal digestion, given the reported health benefits of this 


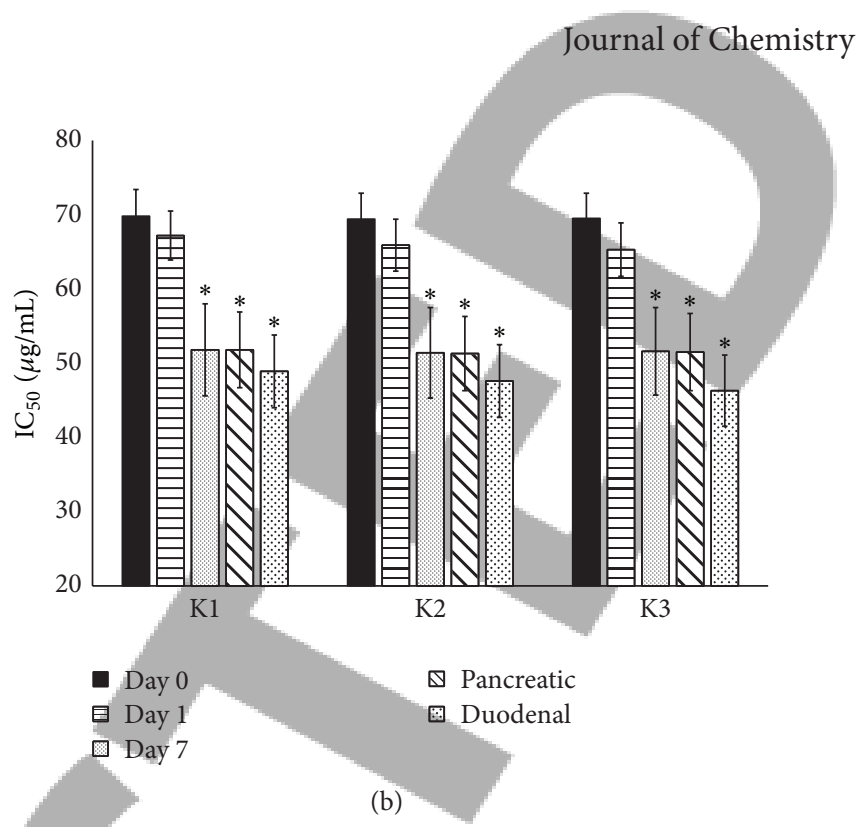

FIgURE 3: Changes in the (a) $\alpha$-amylase and (b) $\alpha$-glucosidase inhibitory activities of the three Kombucha beverages. Error bars represent the SEM. ${ }^{\#} P<0.05$ versus the value at day 7 (prior to being subjected to the digestion phases).

group of compounds, especially catechin and epicatechin. The structural criteria for compounds to be considered as potent free-radical scavengers are that these should possess either a 3-hydroxy group on unsaturated $\mathrm{C}$ ring, or a 2,3double bond with the $3-\mathrm{OH}$ group and 4-one in the $\mathrm{C}$ ring, or an ortho- $\mathrm{OH}$ substitution pattern in the $\mathrm{B}$ ring where the $\mathrm{OH}$ groups are not glycated [28-30]. Being the major polyphenolic components, catechin and epicatechin fulfill the first and third structural criteria for effective antioxidants. In addition to antioxidant and starch hydrolase inhibitory properties, tea polyphenols have displayed antimicrobial and antimycotic activities in vitro $[31,32]$. Thus, in addition to enhancing the human microbiome with beneficial microbes, the organic compounds produced during the Kombucha fermentation further expand the list of therapeutic effects and benefits gained from the consumption of the fermented beverage.

\section{Conclusions}

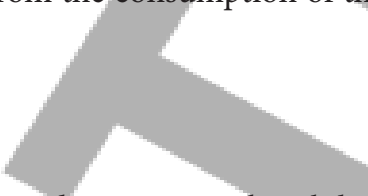

This study was able to demonstrate the ability of the tea fungus to increase the total phenolics, antioxidant activity, and starch hydrolase inhibitory activities, due to the increase in phenolic compounds. Three types of Kombucha pellicles were studied individually as well as in comparison with each other. Also, this study was able to demonstrate the statistically significant increase $(P<0.05)$ in total phenolics, antioxidant activity, and starch hydrolase inhibitory activities after subjecting the fermented beverage to an in vitro digestion model. It was also observed that the $\alpha$-amylase inhibitory activity in particular was increased after the fermentation process, whereby this increase could be associated with the increase in the total phenolics content as well as the increased presence of compounds which have the ability to inhibit $\alpha$-amylase produced during the fermentation process. The increase in starch hydrolase inhibitory activity contributes in enhancing the health and wellness; thus this beverage can be considered as a functional food with notable therapeutic effects. The tea fermented with K3 pellicle was discovered to be the better Kombucha beverage in terms of having the highest antioxidant and starch hydrolase inhibitory activity following fermentation. Since K3 Kombucha sample contains Lactobacillus spp., this beverage can be used as a potentially good probiotic supplement. Finally, the study can be used as a platform to carry out further studies based on different microbial compositions and their effect on changing the chemical composition of Kombucha beverage.

\section{Conflict of Interests}

The authors report no conflict of interests, financial or otherwise.

\section{Acknowledgment}

The financial and analytical support provided by the National Institute of Fundamental Studies, Hantane Road, Kandy, Sri Lanka, is acknowledged.

\section{References}

[1] C. M. Hasler, A. S. Bloch, C. A. Thomson, E. Enrione, and C. Manning, "Position of the American Dietetic Association: functional foods," Journal of American Diabetic Association, vol. 104, pp. 814-826, 2004.

[2] N. Yavari, M. M. Assadi, M. B. Moghadam, and K. Larijani, "Optimizing glucuronic acid production using tea fungus on grape juice by response surface methodology," Australian Journal of Basic and Applied Sciences, vol. 5, no. 11, pp. 1788-1794, 2011.

[3] T. Srihari and U. Satyanarayana, "Changes in free radical scavenging activity of Kombucha during fermentation," Journal of 
Pharmaceutical Sciences and Research, vol. 4, no. 11, pp. 19781981, 2012.

[4] N. Kabiri, M. Setorki, and M. A. Darabi, "Protective effects of kombucha tea and silimarin against thioacetamide induced hepatic injuries in wistar rats," World Applied Sciences Journal, vol. 27, no. 4, pp. 524-532, 2013.

[5] Y. H. Lee, C. Choo, M. I. Watawana, N. Jayawardena, and V. Y. Waisundara, "Kombucha 'tea fungus' enhances the tea polyphenol contents, antioxidant activity and alpha-amylase inhibitory activity of five commonly consumed teas," Journal of Functional Foods, 2014.

[6] M. I. Watawana, N. Jayawardena, and V. Y. Waisundara, "Enhancement of the functional properties of coffee through fermentation by 'tea fungus' (Kombucha)," Journal of Food Processing and Preservation, 2015.

[7] M. I. Watawana, N. Jayawardena, C. Choo, and V. Y. Waisundara, "Application of the Kombucha 'tea fungus' for the enhancement of antioxidant and starch hydrolase inhibitory properties of ten herbal teas," Food Chemistry, vol. 194, pp. 304311, 2016.

[8] A. J. Marsh, O. O’Sullivan, C. Hill, R. P. Ross, and P. D. Cotter, "Sequence-based analysis of the bacterial and fungal compositions of multiple kombucha (tea fungus) samples," Food Microbiology, vol. 38, pp. 171-178, 2014.

[9] W. N. Goh, A. Rosma, B. Kaur, A. Fazilah, A. A. Karim, and R. Bhat, "Fermentation of black tea broth (kombucha): effects of sucrose concentration and fermentation time on the yield of microbial cellulose," International Food Research Journal, vol. 19, no. 1, pp. 109-117, 2012.

[10] C. Chen and B. Y. Liu, "Changes in major components of tea fungus metabolites during prolonged fermentation," Journal of Applied Microbiology, vol. 89, no. 5, pp. 834-839, 2000.

[11] C. Dufresne and E. Farnworth, “Tea, Kombucha, and health: a review," Food Research International, vol. 33, no. 6, pp. 409-421, 2000.

[12] R. Jayabalan, R. V. Malbaša, E. S. Lončar, J. S. Vitas, and M. Sathishkumar, "A review on kombucha tea-microbiology, composition, fermentation, beneficial effects, toxicity, and tea fungus," Comprehensive Reviews in Food Science and Food Safety, vol. 13, no. 4, pp. 538-550, 2014.

[13] N. Jayawardena, M. I. Watawana, and V. Y. Waisundara, "Evaluation of the total antioxidant capacity, polyphenol contents and starch hydrolase inhibitory activity of ten edible plants in an in vitro model of digestion," Plant Foods for Human Nutrition, vol. 70, no. 1, pp. 71-76, 2015.

[14] D. Huang, B. X. Ou, M. Hampsch-Woodill, J. A. Flanagan, and E. K. Deemer, "Development and validation of oxygen radical absorbance capacity assay for lipophilic antioxidants using randomly methylated $\beta$-cyclodextrin as the solubility enhancer," Journal of Agricultural and Food Chemistry, vol. 50, no. 7, pp. 1815-1821, 2002

[15] R. L. Prior, H. Hoang, L. Gu et al., "Assays for hydrophilic and lipophilic antioxidant capacity (oxygen radical absorbance capacity $\left(\mathrm{ORAC}_{\mathrm{FL}}\right)$ ) of plasma and other biological and food samples," Journal of Agricultural and Food Chemistry, vol. 51, no. 11, pp. 3273-3279, 2003.

[16] T. Liu, L. Song, H. Wang, and D. Huang, "A high-throughput assay for quantification of starch hydrolase inhibition based on turbidity measurement," Journal of Agricultural and Food Chemistry, vol. 59, no. 18, pp. 9756-9762, 2011.

[17] W. K. Lee, L. L. Wong, Y. Y. Loo, S. Kasapis, and D. J. Huang, "Evaluation of different teas against starch digestibility by mammalian glycosidases," Journal of Agricultural and Food Chemistry, vol. 58, no. 1, pp. 148-154, 2010.

[18] L. Ryan, O. O'Connell, L. O'Sullivan, S. A. Aherne, and N. M. O'Brien, "Micellarisation of carotenoids from raw and cooked vegetables," Plant Foods for Human Nutrition, vol. 63, no. 3, pp. 127-133, 2008.

[19] R. Jayabalan, S. Marimuthu, P. Thangaraj et al., "Preservation of kombucha tea-effect of temperature on tea components and free radical scavenging properties," Journal of Agricultural and Food Chemistry, vol. 56, no. 19, pp. 9064-9071, 2008.

[20] S. N. Thanaraj and R. Seshadri, "Influence of polyphenol oxidase activity and polyphenol content of tea shoot on quality of black tea," Journal of the Science of Food and Agriculture, vol. 51, no. 1, pp. 57-69, 1990.

[21] N. O. Kozyrovska, O. M. Reva, V. B. Goginyan, and J.-P. de Vera, "Kombucha microbiome as a probiotic: a view from the perspective of post-genomics and synthetic ecology," Biopolymers and Cell, vol. 28, no. 2, pp. 103-113, 2012.

[22] S. L. Markov, R. V. Malbaša, M. J. Hauk, and D. D. Cvetković, "Investigation of tea fungus associations. I. The yeasts," Acta Periodica Technologica, vol. 32, pp. 133-138, 2001.

[23] R. V. Malbaša, E. S. Lončar, J. S. Vitas, and J. M. ČanadanovićBrunet, "Influence of starter cultures on the antioxidant activity of kombucha beverage," Food Chemistry, vol. 127, no. 4, pp. 17271731, 2011.

[24] J. Reiss, "Influence of different sugars on the metabolism of the tea fungus," Zeitschrift für Lebensmittel-Untersuchung und -Forschung, vol. 198, no. 3, pp. 258-261, 1994.

[25] P. J. Blanc, "Characterization of the tea fungus metabolites," Biotechnology Letters, vol. 18, no. 2, pp. 139-142, 1996.

[26] R. Jayabalan, P. Subathradevi, S. Marimuthu, M. Sathishkumar, and K. Swaminathan, "Changes in free-radical scavenging ability of kombucha tea during fermentation," Food Chemistry, vol. 109, no. 1, pp. 227-234, 2008.

[27] L. R. Fukumoto and G. Mazza, "Assessing antioxidant and prooxidant activities of phenolic compounds," Journal of Agricultural and Food Chemistry, vol. 48, no. 8, pp. 3597-3604, 2000.

[28] S.-C. Chu and C. H. Chen, "Effects of origins and fermentation time on the antioxidant activities of kombucha," Food Chemistry, vol. 98, no. 3, pp. 502-507, 2006.

[29] D. A. Balentine, S. A. Wiseman, and L. C. M. Bouwens, "The chemistry of tea flavonoids," Critical Reviews in Food Science and Nutrition, vol. 37, no. 8, pp. 693-704, 1997.

[30] C. J. Greenwalt, K. H. Steinkraus, and R. A. Ledford, "Kombucha, the fermented tea: Microbiology, composition, and claimed health effects," Journal of Food Protection, vol. 63, no. 7, pp. 976-981, 2000.

[31] C. Pasha and G. Reddy, "Nutritional and medicinal improvement of black tea by yeast fermentation," Food Chemistry, vol. 89, no. 3, pp. 449-453, 2005.

[32] H.-L. Alakomi, R. Puupponen-Pimiä, A.-M. Aura et al., "Weakening of Salmonella with selected microbial metabolites of berry-derived phenolic compounds and organic acids," Journal of Agricultural and Food Chemistry, vol. 55, no. 10, pp. 39053912, 2007. 